\title{
Comunicação breve Anti-vacinação, um movimento com várias faces e consequências
}

\author{
Brief communication
}

Anti-vaccination, a movement with multiple faces and its consequences

Comunicación breve

Anti-vacunación, un movimiento multifacético y consecuencias

Vitor Laerte Pinto Junior ${ }^{1}$

\begin{abstract}
Resumo
O movimento anti-vacinação tem ganhado força no mundo inteiro, apesar dos inquestionáveis avanços obtidos com as vacinas na redução drástica da incidência das doenças contagiosas. As causas para este avanço ainda são temas de discussão e pesquisa, mas a ignorância, a facilidade da disseminação de informações falsas e a ascensão de políticas populistas têm sido implicadas. O grande desafio para o futuro será a dicotomia entre o interesse da saúde pública e as liberdades individuais.
\end{abstract}

Palavras-chave: Movimento contra vacinação. Saúde pública. Individualidade.

\begin{abstract}
The anti-vaccination movement has gained worldwide strength despite the undeniable advances in vaccines in drastically reducing the incidence of contagious diseases. The causes for this breakthrough are still issues of discussion and research, but ignorance, ease of dissemination of false information, and the rise of populist policies have been implicated. The major challenge for the future will be the dichotomy between the interest of public health and individual freedoms.
\end{abstract}

Keywords: Movement against vaccination. Public health. Individuality.

\section{Resumen}

El movimiento contra la vacunación ha ganado fuerza en todo el mundo a pesar de los innegables avances en las vacunas para reducir drásticamente la incidencia de enfermedades contagiosas. Las causas de este avance aún son temas de discusión e investigación, pero la ignorancia, la facilidad de difusión de información falsa y el auge de las políticas populistas han sido implicados. El principal desafío para el futuro será la dicotomía entre el interés de la salud pública y las libertades individuales.

Palabras-Ilave: Movimiento contra la vacunación. Salud pública. Individualidad.

\footnotetext{
1 Doutor e Pós- Doutor em Medicina Tropical. Médico infectologista do Serviço de Infectologia do Hospital de São Bernardo (Centro Hospitalar de Setúbal), Setúbal, Portugal. E-mail: vitorlaerte@gmail.com
} 
A hesitação contra a imunização é prática antiga, ocorria mesmo antes da descoberta da vacina como a conhecemos hoje. A variolização foi uma das primeiras estratégias utilizadas para se evitar a ocorrência de uma doença de importância sanitária. Consistia na inoculação do conteúdo purulento retirado da lesão de doentes em indivíduos não imunes e era realizada desde épocas remotas. Baseava-se na observação de que aqueles que sobrevivessem ao episódio de varíola adquiriam imunidade duradora. Foi introduzida na Europa no início do século XVIII e adotada com certa cautela, pois os inoculados apresentavam risco de adoecer e disseminar a doença (1).

A variolização também não era bem vista pela Igreja Católica por considerar a prática antinatural, um caso interessante sobre os primórdios dos movimentos anti-vacinação foi a morte precoce por varíola do Príncipe do Brasil, D. José, filho de D. Maria I e herdeiro do Trono do Reino de Portugal e Algarve. Várias casas europeias já haviam realizado o procedimento nos seus herdeiros, mas D. Maria I, por ser muito religiosa, negou-se a aplicálo nos seus dois filhos. Acredita-se que a culpa pela morte precoce do Príncipe tenha sido um forte motivo para o surgimento da doença psiquiátrica que acometeu a Rainha até a sua morte (2).

Em 1770, Edward Jenner observou que a inoculação da varíola bovina (cow pox) tornava as pessoas imunes contra a varíola humana e ainda evitava os inconvenientes da variolização. A aplicação da vacina, assim denominada por ser originária da vaca (vaccinae em latim), por apresentar excelente custo benefício e comprovada eficácia, foi adotada pelas autoridades sanitárias de maneira compulsória, gerando críticas e descontentamento por parte da população (1).

O primeiro movimento anti-vacinação organizado surgiu com o estabelecimento de leis pró-vacinação entre 1840-1853, promulgado pelo governo inglês, que tornava a vacinação compulsória de crianças e pobres e determinava punições para os refratários. Essa lei gerou imediata reação negativa da população tendo como argumento principal a quebra do princípio da liberdade individual e o medo do estabelecimento da tirania médica. Uma liga anti-vacinação foi criada e, em 1867, uma nova lei foi aprovada dando liberdade aos pais de assumirem a responsabilidade de não vacinarem os seus filhos (3).

De maneira semelhante, mas mais tardiamente, uma lei que obrigava a vacinação contra a varíola foi aprovada no Brasil em 1904, gerando a chamada revolta da vacina. Também foi um movimento social, desorganizado e de curta duração, e que teve como fator 
desencadeante a obrigatoriedade da vacinação estabelecida por Oswaldo Cruz, que ocupava o cargo de diretor da Junta de Higiene, paralelo ao de ministro da saúde nos dias atuais (4).

Entre as décadas de 40 e 70, a vacinação teve a sua era de ouro com a descoberta de novos produtos, desenvolvimento da indústria e a eliminação de várias doenças epidêmicas (5). O ápice desta era foi a certificação global da erradicação da varíola em 1980 (6).

Neste período os programas nacionais de imunização foram criados e desenvolvidos em diversos países, inclusive nos ditos subdesenvolvidos, o que evitou inúmeras mortes, principalmente das crianças. Pode-se citar alguns exemplos como a poliomielite, doença viral causadora de epidemias, sendo a manifestação clínica mais temida as que envolvem o sistema nervoso central e que podem culminar com sequelas motoras duradouras (paralisia infantil). Desde 1988, a incidência da doença caiu mais de $99 \%$ em todo mundo, sendo eliminada das Américas em 1991 e no Brasil, em 1994. Dos três sorotipos de vírus selvagens, o poliovírus 2 foi erradicado em 1999, o poliovírus 3 não é notificado desde 2012, restando a transmissão atualmente somente em três países: Nigéria, Paquistão e Afeganistão (7).

Outro exemplo da eficácia da vacina nas políticas de controle e eliminação de doenças é o caso do sarampo, doença viral altamente contagiosa declarada eliminada das Américas em 2016. De acordo com os dados da Organização Mundial da Saúde (OMS), o número de casos de sarampo no mundo no início da década de 80 chegava a mais de 4 milhões por ano, com o aumento da cobertura vacinal para $90 \%$ (considerando-se a primeira dose da vacina), os casos chegaram para 170 mil em 2017 (8).

No entanto, mesmo com os avanços obtidos e os resultados comprovados, o movimento anti vacinação tomou força no fim da década de 70 (9). As causas para o fortalecimento desse movimento ainda são motivo de intenso debate e de pesquisas, mas didaticamente pode-se dizer que os indivíduos antivacionistas se distribuem em espectros de dois polos: os ignorantes que não entendem o método científico e de conceitos matemáticos como risco e probabilidade e os que se utilizam do uso da desinformação e coação (6).

Os instrumentos utilizados pelos movimentos anti-vacinação incluem, nomeadamente, a instauração de procedimentos legais contra a indústria farmacêutica e 
governos e o uso da política e de teorias sociais para embasarem a sua prática (6). O meio de divulgação e de aquisição de seguidores destes grupos é basicamente a imprensa e a internet, amparados pela ausência de culpabilização pelas consequências funestas das suas práticas na saúde pública (10).

Nos Estados Unidos, a indústria de vacinas vem sofrendo processos judiciais que, adicionalmente à baixa lucratividade do setor, têm inviabilizado a produção e desenvolvimento de imunobiológicos, e por isso muitas empresas têm encerrado a sua linha de vacinas. Recentemente, a Corte Europeia de Justiça decidiu que os indivíduos podem processar os laboratórios sem a necessidade de apresentarem provas que justifiquem o processo; essa decisão teve como argumento o desequilíbrio de poder existente entre as partes (11).

A disseminação de páginas com conteúdo anti-vacinação nas redes sociais tem sido um fator preocupante e o próprio Facebook tem tomado medidas para dificultar a partilha de informações falsas. Na rede mundial há notícia de mais de 400 sites de internet, geralmente bem construídos e muito atrativos, onde são expostos argumentos contra a prática vacinal, a maior parte sem qualquer embasamento científico (12). Com intuito de contra-argumentar, os Centros de Controle e Prevenção de Doenças (CDC, em inglês) e a OMS mantêm uma página contendo evidências acerca da segurança e eficácia das vacinas (13).

No continente europeu, onde se encontra a maior proporção de resistência à vacinação, recentemente tem-se investigado a possibilidade de ideologias políticas influenciarem o modo com o qual as pessoas tomam decisões em relação à vacinação. Tenta-se associar a ascensão de partidos populistas ao poder com a diminuição da cobertura vacinal. $O$ argumento principal é que mudanças sociais e políticas, como a imigração e a crise económica de 2008 , tenham abalado a confiança dos cidadãos no sistema de bemestar social, incluindo-se as políticas de saúde pública (14).

Alguns exemplos de surtos causados pela queda da imunidade de crianças e jovens pela negação da vacinação são cada vez mais frequentes. A prefeitura de Nova lorque decretou emergência de saúde pública em alguns bairros da cidade após a deteção de 285 casos de sarampo, na maioria em indivíduos menores de 18 anos. O surto afetou mais a comunidade de judeus ortodoxos, que sofreu propaganda de um grupo anti-vacinação que propagou que as vacinas se associavam ao autismo e que era contra a religião judaica (15). 
Em decorrência da crise humanitária por que passa a Venezuela, os refugiados que cruzaram a fronteira com o Brasil levaram o vírus, onde encontrou as coberturas vacinais abaixo do limiar epidêmico (16). Essa situação levou à transmissão sustentada da doença e à perda da certificação de país livre de sarampo. Foram mais de 10 mil casos em 2018, concentrando-se na Região Norte. Até o momento não se sabe os motivos para a queda da cobertura vacinal, mas, além do relaxamento dos programas governamentais e da displicência paterna em vacinar os filhos, é possível que o movimento anti-vacinação esteja tomando força no Brasil (17).

Com mais de um século de implantação e inúmeros aperfeiçoamentos, é indiscutível os benefícios alcançados com a massificação das vacinas. A eliminação e o controle de diversas doenças, que antes causavam grande morbidade e letalidade, evitaram verdadeiras tragédias e beneficiaram principalmente as crianças.

É inquestionável que os avanços na saúde pública obtidos com a vacinação estão ameaçados com a crescente diminuição da cobertura vacinal. Novos surtos de doenças que anteriormente estavam controladas vão aumentar; a OMS declarou que o número de casos de sarampo aumentou em 300 \% nos primeiros meses de 2019 (8). Como consequência da diminuição do uso de vacinas e a constante ameaça de processos sofridos pela indústria, pode haver colapso do sistema de fabricação e comercialização de imunobiológicos. É bem possível que a demanda por esses produtos seja maior que a sua produção em pouco tempo, causando quebras de estoque e aumento do preço, obviamente prejudicando aos países mais pobres.

O maior desafio a ser enfrentado pelas autoridades sanitárias, nacionais e supranacionais, será o controle da informação na internet perante o aumento da influência dos grupos anti-vacinação no mundo (17). Diante das ações a serem tomadas para este último fim, hoje como no passado, levantam-se as questões: como impedir a circulação de falsas informações sem ameaçar a liberdade de expressão? E, como preservar o direito à saúde dos indivíduos sem afetar a liberdade individual de escolha?

\section{Referências}

1. Bhebehani AM. The Smallpox Story: Life and Death of an Old Disease. Microbiological Reviews, 1983, 47 (4):455-509.

2. Rezzutti P. D. Pedro: a história não contada. São Paulo: LeYa; 2015. 
3. Wolfe RM, Sharp LK. Anti-vaccinationists past and present. BMJ, 2002, 325(7361):430432.

4. Sevcenko N. A Revolta da Vacina. São Paulo: Cosac \& Naify; 2010.

5. Greenwood B. The contribution of vaccination to global health: past, present and future. Philos Trans R Soc Lond B Biol Sci. 2014;369(1645):20130433. Published . doi:10.1098/rstb.2013.0433

6. Poland GA, Jacobson RM. The Age-Old Struggle against the Antivaccinationists. The New England Journal of Medicine, 2011, 364(2):97-99.

7. World Health Organization. [Relatório Técnico]. Polio: Eradication. Genebra: WHO; 2019.

8. World Health Organization. Measles and Rubella Surveillance Data. Genebra;2019 [15/04/2019]. Disponível em:

https://www.who.int/immunization/monitoring_surveillance/burden/vpd/surveillance_type/act ive/measles_monthlydata/en/ [acesso em 25/04/2019].

9. Andre FE, Booy R, Bock HL, et al. Vaccination greatly reduces disease, disability, death and inequity worldwide. Bull World Health Organ. 2007;86(2):140-146.

doi:10.2471/BLT.07.040089

10. Evrony A, Caplan A. The overlooked dangers of anti-vaccination groups' social media presence. Hum Vaccin Immunother. 2017;13(6):1-2. doi:10.1080/21645515.2017.1283467

11. Foreign Policy. Science Won't Save Vaccines From Lawsuits Anymore. Washington, 2017. Disponível em: https://foreignpolicy.com/2017/06/26/science-wont-save-vaccinesfrom-lawsuits-anymore/ [Acesso em 20.abr.2019].

12. Hotez P. America and Europe's new normal: the return of vaccine-preventable diseases. Pediatric Research. 2019; 85: 912-914.

13. World Health Organization. Six common misconceptions about immunization. Genebra, 2019. Disponível em:

https://www.who.int/vaccine_safety/initiative/detection/immunization_misconceptions/en/ [Acesso em 20.abr.2019].

14. Kennedy J. Populist politics and vaccine hesitancy in Western Europe: an analysis of national-level data. European Journal of Public Health. 2019: 1-5.

15. Cable News Network (CNN). A measles outbreak is dividing families in this Orthodox Jewish community. Passover could make it worse. Atlanta, 2019. Disponível em: https://edition.cnn.com/2019/04/19/health/new-york-measles-outbreak-passoverwilliamsburg/index.html [Acesso em 20.abr.2019]. 
Cadernos Ibero-Americanos

de Direito Sanitário

Cuadernos lberomericanos

de Derecho Sanitario

16. Paniz-Mondolfi AE, Tami A, Grillet ME, et al. Resurgence of Vaccine-Preventable Diseases in Venezuela as a Regional Public Health Threat in the Americas. Emerging Infectious Diseases. 2019;25(4):625-632. doi:10.3201/eid2504.181305.

17. Cousins S. Measles: a global resurgence. The Lancet Infectious Diseases. 2019;19(4):362-363.

Como citar esse artigo:

Junior, VLP. Anti-vacinação, um movimento com várias faces e consequências. Cadernos Ibero-Americanos de Direito Sanitário. 2019 abr./jun.; 8(2): 116-122. 